Research Paper

\title{
Bioactivities of ethanol extract from the Antarctic freshwater microalga, Chloromonas sp.
}

Sung-Suk Suh¹, Eun Jin Yang², Sung Gu Lee1,3, Ui Joung Youn¹, Se Jong Han, ${ }^{1}$, Il-Chan Kim,3 and Sanghee Kim ${ }^{1,3}{ }^{\square}$

1. Division of Polar Life Sciences, Korea Polar Research Institute, Incheon, 21990, Republic of Korea;

2. Department of Polar Ocean Environment, Korea Polar Research Institution, Incheon, 21990, Republic of Korea;

3. Department of Polar Science, University of Science and Technology, Incheon, 21990, Republic of Korea.

$\triangle$ Corresponding author: Dr. Sanghee Kim, Email: sangheekim@kopri.re.kr Tel: 82-32-760-5515 Fax: 82-32-760-5509

(c) Ivyspring International Publisher. This is an open access article distributed under the terms of the Creative Commons Attribution (CC BY-NC) license (https://creativecommons.org/licenses/by-nc/4.0/). See http://ivyspring.com/terms for full terms and conditions.

Received: 2016.12.11; Accepted: 2017.03.29; Published: 2017.04.28

\begin{abstract}
Cancer is the principal cause of human death and occurs through highly complex processes that involve the multiple coordinated mechanisms of tumorigenesis. A number of studies have indicated that the microalgae extracts showed anticancer activity in a variety of human cancer cells and can provide a new insight in the development of novel anti-cancer therapy. Here, in order to investigate molecular mechanisms of anticancer activity in the Antarctic freshwater microalga, Chloromonas sp., we prepared ethanol extract of Chloromonas sp. (ETCH) and performed several in vitro assays using human normal keratinocyte $(\mathrm{HaCaT})$ and different types of cancer cells including cervical, melanoma, and breast cancer cells (HeLa, A375 and Hs578T, respectively). We revealed that ETCH had the antioxidant capacity, and caused significant cell growth inhibition and apoptosis of cancer cells in a dose-dependent manner, whereas it showed no anti-proliferation to normal cells. In addition, ETCH had a significant inhibitory effect on cell invasion without the cytotoxic effect. Furthermore, ETCH-induced apoptosis was mediated by increase in pro-apoptotic proteins including cleaved caspase- 3 and $\mathrm{p} 53$, and by decrease in anti-apoptotic protein, $\mathrm{Bcl}-2$ in ETCH-treated cancer cells. Taken together, this work firstly explored the antioxidant and anticancer activities of an Antarctic freshwater microalga, and ETCH could be a potential therapeutic candidate in the treatment of human cancer.
\end{abstract}

Key words: Bioactivities, ethanol extract, Chloromonas sp.

\section{Introduction}

According to American Cancer Society (Cancer Facts and Figures 2016) it is estimated that the incidence of childhood cancer accounts for a large proportion of all cancer cases. In 2016, it was estimated that there are 10,380 new cases of cancer and among them 1,250 deaths of children occur due to cancer. Many scientists around the world are endeavoring to develop novel targeted therapies in human cancer treatments, which are capable for selectively killing cancer cells, not harmful to normal cells. For the successful development of such therapies, it is primarily necessary to better understand physiological and molecular differences between caner and normal cells. Therefore, the studies of new anti-cancer therapy can in part, improve comprehension of cancer biology mechanisms, selectively targeting molecular pathways thought to be critical for tumor survival, growth, and metastases [1-3]. In fact, in the last few decades the increasing incidence of human cancer has led to the progressive development of new anticancer agents through more systematic and scientific validation of a wide range of synthetic and natural substrates [4,5]. According to the Pharmaceutical Research and Manufacturers of America, more than 800 anti-cancer agents have been shown to be effective in clinical trial. Among them many drugs were derived from the natural sources such as plant and microorganisms against various 
different types of cancers such as prostate, breast, lung and colon cancers. In addition, anticancer activities of numerous natural products are currently being investigated to identify potential anticancer agents which could improve the efficacy of specific targeted therapies against cancer [6-10]. In particular, anticancer agents from indefinite uncharacterized organisms in the extreme environments such as marine and Antarctic area have aroused considerable interest in pharmaceutical industries because they have evolved their own defense mechanisms by secreting toxic secondary metabolites, which are explored in anticancer studies and plays an important role in therapeutic strategies [11, 12].

Microalgae are diverse group of unicellular photosynthetic eukaryotes and consist in at least 40,000-70,000 species belonging to various phyla such as Cyanophyta (bluegreen algae), Rhodophyta (red algae), Chlorophyta (green algae), Pyrrophyta, Cryptophyta, Haptophyta, Heterokontophyta, and Streptophyta [13, 14]. Microalgae have adapted to a wide range of environments and display their worldwide distribution. This great ecological plasticity consequently has led to be a rich source of genetic and metabolic diversity, which is compatible with a wide variety of interesting and useful secondary metabolites. Thus, they have attracted attention in regard to pharmacological and medicinal values in various parts of the world and emphasized that research on their metabolites are useful for the cure and for the alleviation of human diseases [15, 16]. Recent studies have indicated that bioactive resources from many algae may have pharmaceutical and health-promoting properties, and the research efforts that need to be made to facilitate the optimal development of algae-derived resources were highlighted in pharmacological industry [17-19]. In particular, considerable emerging evidences suggest that some algae-derived compounds seem to have anticancer activities through the modulation of multiple cellular mechanisms, including cellular cytotoxicity, inhibition of invasion and the promotion of apoptosis of cancer cells [20,21]. Thus, the cellular and molecular studies have shown algae-derived compounds to be potent naturally occurring anticancer compounds which effectively prevent tumorigenesis $[22,23]$. For examples, fucoxanthin is a carotenoid found in microalgae, diatom, and brown seaweeds and exhibited potential anticancer activity, inhibiting the growth of cancer cells in a concentration dependent manner along with the induction of cancer suppressor genes and cell cycle arrest, but not apoptosis [24, 25].

Accumulating data for the algae-derived anticancer compounds can provide new insights in the development of the targeted and effective therapies against human cancer. Further consideration deserves to be given to their biological function in the cellular mechanisms of particular cancers that display different degrees of cytotoxic response to them. In the present study, ethanol extract was obtained from Chloromonas sp., an Antarctic freshwater microalga, and used for the evaluation of the mechanism, at least in part, of such antioxidant and anticancer activities using in vitro cell based assays. This work firstly explored the antioxidant and anticancer activities of an Antarctic freshwater microalga, Chloromonas sp.

\section{Materials and Methods}

\section{Sample collection and preparation}

The Antarctic freshwater microalga, Chloromonas sp., used in the present study was collected from freshwater near King Sejong Antarctic Station (62 $12^{\prime}$ $\mathrm{S}, 58^{\circ} 47^{\prime} \mathrm{W}$ ) in 2014 . Ten gram of dried microalgae material was kept in $50 \mathrm{~mL}$ conical tubes and added $20 \mathrm{~mL}$ of solvent such as ethanol. The conical tubes were kept in a reciprocating shaker for $24 \mathrm{~h}$ for continuous agitation at $150 \mathrm{rev} / \mathrm{min}$ for mixing and also complete elucidation of bioactive compounds to dissolve in the respective solvent. Then, the conical tubes were centrifuged $\left(4^{\circ} \mathrm{C}, 15 \mathrm{~min}, 4000 \mathrm{rpm}\right)$ for collection of supernatants, followed by filtration with Whatman no. 1 filter paper. The solvent from the extract was removed by using rotary vacuum evaporator with the water bath temperature of $50^{\circ} \mathrm{C}$. Finally, the residues were collected and used for the experiment.

\section{DPPH radical scavenging assay}

The DPPH assay was performed by slightly modified method in previous study [26]. A solution of $1 \mathrm{mM}$ DPPH in $80 \%(\mathrm{v} / \mathrm{v})$ ethanol was stirred for $40 \mathrm{~min}$. In this method, $1.2 \mathrm{mg}$ of DPPH free radical was dissolved in $50 \mathrm{~mL}$ of methanol to prepare its stock solution. The working solution of DPPH was obtained by diluting its stock solution with methanol until absorbance of the solution was adjusted to $0.650 \pm 0.020$ at $517 \mathrm{~nm}$. Then, this solution $(2.97 \mathrm{~mL})$ was added to $30 \mu \mathrm{L}$ of standard or sample at different concentration $(0.2,0.4,0.6,0.8,1.0 \mu \mathrm{g} / \mathrm{mL})$. After incubating the mixture in the dark for $30 \mathrm{~min}$, absorbance was measured at $517 \mathrm{~nm}$. Ascorbic acid was used as a reference standard compound. DPPH scavenging affect $(\%)=100 \times$ (Acontrol $\mathrm{A}_{\text {Sample }}$ / / $\mathrm{A}_{\text {Control. }} \mathrm{IC}_{50}$ value, which is the concentration of the sample required to inhibit $50 \%$ of radical, was then calculated by plotting the percentage of scavenging activity against the different concentrations $(0.2-1.0 \mu \mathrm{g} / \mathrm{mL})$. 


\section{ABTS radical scavenging assay}

The scavenging activity was measured as described in previous work [27] with slight modifications. ABTS (Sigma) was dissolved in ethanol to make a final concentration of $7 \mathrm{mM}$ and then mixed with a potassium persulfate solution to make a final concentration of $2.45 \mathrm{mM}$. The mixture was kept in the dark at room temperature for $12-16 \mathrm{~h}$ to allow completion of radical generation. The ABTS.+ stock solution was diluted with $95 \%$ ethanol to keep its absorbance at $734 \mathrm{~nm}$ within $0.70 \pm 0.02$ measured on a spectrophotometer. To determine the scavenging activity, $10 \mu \mathrm{L}$ of each sample was mixed with $990 \mu \mathrm{L}$ of ABTS.+ ${ }^{+}$working solution, and the absorbance was measured at $734 \mathrm{~nm}$ after incubation for $6 \mathrm{~min}$ at $25^{\circ} \mathrm{C}$ in the dark. Ascorbic acid was used as the positive control. ABTS scavenging affect $(\%)=100 x$ (AControl - Asample) / A Control. $_{\text {. }}$

\section{Cell lines and culture}

The human keratinocyte cell line (HaCaT) and cancer cell lines (HeLa, A375, and Hs578) were purchased from the American Type Culture Collection (ATCC). The cells were maintained in Dulbecco's modified Eagle's medium (DMEM; Gibco/Invitrogen) with $10 \%$ Fetal Bovine Serum (FBS) in $37{ }^{\circ} \mathrm{C}$ humidified incubator containing $5 \% \mathrm{CO}_{2}$. Cells were plated at a density of $0.5 \times 10^{6} /$ well in 6 -well plates and grown overnight. For maintenance of cell culture, the medium was changed every 2-3 days and cells split at $80 \%$ confluence via trypsinization. Cells were seeded at an optimal density of $14 \times 10^{3} / \mathrm{cm}^{2}$.

\section{Cell growth inhibition assay and morphological observations}

Cells were plated at density of $1 \times 10^{3}$ cells per well in 96-well plates in triplicate and incubated at $37^{\circ} \mathrm{C}$ with $5 \% \mathrm{CO}_{2}$ in a humidified incubator. Cell viability was measured with the 3-(4, 5-dimethylthiazol-2-yl)-2, 5-dipheniltetrazolium bromide (MTT)-Cell Titer 96AQueous One Solution Cell Proliferation Assay (Promega) and was analyzed over a period of three days. At every $24 \mathrm{~h}$ interval, 20 $\mu 1$ MTT was added to detect metabolically active cells. The plate was incubated for $1 \mathrm{~h}$ and analyzed in a Multilabel Counter (Bio-Rad Laboratories). Cell morphological changes were directly recorded using a phase-contrast inverse microscope fitted with digital camera (Nikon). Later, the plates were stained with $0.5 \%$ of crystal violet and scanned for records.

\section{Annexin V/propidium iodide staining apoptosis assay}

For cell apoptosis assay, Annexin V-FITC apoptosis detection kit (BD Biosciences) was used to assess the apoptotic effect of ETCH. For Annexin V staining, HaCaT and HeLa cells (control, ETCH-treated group) were harvested by typsinization, washed twice with cold PBS, and then resuspended in $100 \mu \mathrm{l} 1 \times$ binding buffer $\left(\sim 1 \times 10^{5}\right.$ cells/mL) containing $5 \mu \mathrm{l}$ and $2 \mu \mathrm{l}$ of annexin V-FITC and PI, respectively. After cells were incubated for 15 min at room temperature in the dark, $400 \mu l$ of $1 \times$ binding buffer was added to each tube and then cells were detected using flow cytometry within $1 \mathrm{~h}$.

\section{Western blot analysis}

Samples were lysed on ice in RIPA buffer (50 $\mathrm{mM}$ Tris $\mathrm{Cl}$, pH 7.5, $150 \mathrm{mM} \mathrm{NaCl}, 2 \mathrm{mM}$ EDTA, 1\% NP-40, 0.5\% Na-deoxycholate). Total protein (50 $\mu \mathrm{g})$ from each sample was separated on a $4-20 \%$ Criterion $^{\mathrm{TM}}$ Tris $\mathrm{HCl}$ precast gel (BioRad) and transferred onto nitrocellulose (NC) membranes. The membrane was incubated at $4^{\circ} \mathrm{C}$ overnight with primary antibody: anti-caspase-3 antibody, anti-Bcl-2 and p53 (Cell Signaling). After probed with secondary antibody IgG conjugated to HRP (Santa Cruz Biotechnology), membrane was developed with enhanced chemiluminescence (Amersham Pharmacia).

\section{Colony forming assay}

$\mathrm{HaCaT}$ and cancer cells were seeded in 6-well plates at a density of 2000 cells/well in triplicate. After incubation for $24 \mathrm{~h}$ of adherence, the cells were treated with or without 12.5 and $25 \mu \mathrm{g} / \mathrm{mL}$ of ETCH for $6 \mathrm{~h}$. Then the cells were maintained with fresh culture medium and replaced every three days until the appearance of colonies with regular change of medium. Colonies were stained with a $0.4 \%$ crystal violet (Sigma) in 50\% methanol and visible colonies were counted.

\section{Invasion assay}

Transwell insert chambers with an $8 \mu \mathrm{m}$ porous membrane (Cell Biolabs) were used for the Invasion assay. Cells $\left(1.6 \times 10^{6}\right.$ cells $\left./ \mathrm{mL}\right)$ were washed three times with PBS and added to the top chamber in serum-free medium containing different concentration of ETCH (1.6 and $3.2 \mu \mathrm{g} / \mathrm{mL})$. The bottom chamber was filled with medium containing $10 \%$ FBS. The ETCH-treated cells were incubated for $48 \mathrm{~h}$ at $37^{\circ} \mathrm{C}$ in a $5 \% \mathrm{CO} 2$ humidified incubator. To quantify invaded cells, cells in the top chamber were removed by using a cotton-tipped swab, and the invaded cells were stained with Cell Stain Solution, visualized under a phase-contrast microscope and photographed. The stained cells were then solubilized with Extraction Solution and measured the OD 560 
$\mathrm{nm}$ in a plate reader.

\section{Statistical analysis}

Mean values and their standard deviations were calculated from three biological replicates. The statistical significance of the difference between means was tested using one-way ANOVA followed by Student's $t$ test; $\mathrm{p}$ values $<0.05$ were considered to indicate statistical significance.

\section{Results}

\section{Antioxidant activity of ETCH}

Recently, a variety of spectrophotometric assays has been adopted to measure antioxidant activity of bioactive compounds, the most popular being 2,2'-azino-bis-3-ethylbenzthiazoline-6-sulphonic acid (ABTS) and 1,1-diphenyl-2-picrylhydrazyl (DPPH) assays, which are based on an electron transfer and involves reduction of a colored oxidant. This property allows visual monitoring of the reaction, and both convenient assay in their application. In this study, for evaluation of free radical scavenging properties of $\mathrm{ETCH}$ we have used two assays: the DPPH radical and the ABTS radical cation assay. As shown in Fig. 1, the DPPH radical scavenging activity of ETCH increased with increase in its concentration, showing the range of $5.87-54.35 \%$ with an $\mathrm{IC}_{50}$ value of 0.97 $\mu \mathrm{g} / \mathrm{mL}$. Ascorbic acid as the reference standard displayed a scavenging activity of $96.8 \%$ at a 0.6 $\mu \mathrm{g} / \mathrm{mL}$ with an $\mathrm{IC}_{50}$ value of $0.12 \mu \mathrm{g} / \mathrm{mL}$. On the other hand, ETCH was able to scavenge the ABTS ++ radicals in a dose-dependent activity, about $56.4 \%$ at 1 $\mu \mathrm{g} / \mathrm{mL}$. The $\mathrm{IC}_{50}$ values of the positive control Ascorbic acid and extract were determined to be 0.18 and $0.95 \mathrm{mg} / \mathrm{mL}$, respectively. Antioxidant capacity by ABTS method was slightly higher than antioxidant capacity by DPPH assay, as compared by student's paired t-test.

\section{Anti-proliferative effects of ETCH on human cancers and normal keratinocyte cells}

To investigate the possibility of using microalgae extract as a potential source for anticancer treatments, three different cancer cell lines (A375, HeLa, and Hs578T) were incubated with various concentration of ETCH for $72 \mathrm{~h}$. Its anti-proliferative effect was assessed by using MTT assay. As shown in Fig. 2, while significantly cytotoxic effects were observed in melanoma and cervical cancer cells, A375 and HeLa, with dose-dependent manner when its concentration $\geq 6.25 \mu \mathrm{g} / \mathrm{mL}$, breast cancer cells, Hs578T, showed anti-proliferative effects at the higher concentration, $12.5 \mu \mathrm{g} / \mathrm{mL}$. Interestingly, when compared with the control group, no significant different difference on the viability of HaCaT was observed in the normal cells, HaCaT, suggesting that the extract is selectively toxic to human cancer cells. These data indicate that ETCH may possess a broad inhibitory on the growth of cancer cells despite having a different degree of anti-proliferation to different types of cancer cells. In addition, the data was also evident by examining the morphology of cells under the microscope. Consistent with cytotoxic assay, significant cell morphology changes such as shrinkage and deformation were detected in cancer cells, not normal cells. In addition, we evaluated the long term effect of microalgae extract on cell proliferation by colony formation assays. Three type of cancer cells treated with ETCH for $6 \mathrm{~h}$ showed inhibition of their colony-forming efficacy during 14 days of culture with regular change of normal medium, every three days. As shown in Fig 3 , colony number decreased significantly in cancer cells treated with ETCH (12.5 and $25 \mu \mathrm{g} / \mathrm{mL})$, whereas not much change of colony number was observed in normal cells.
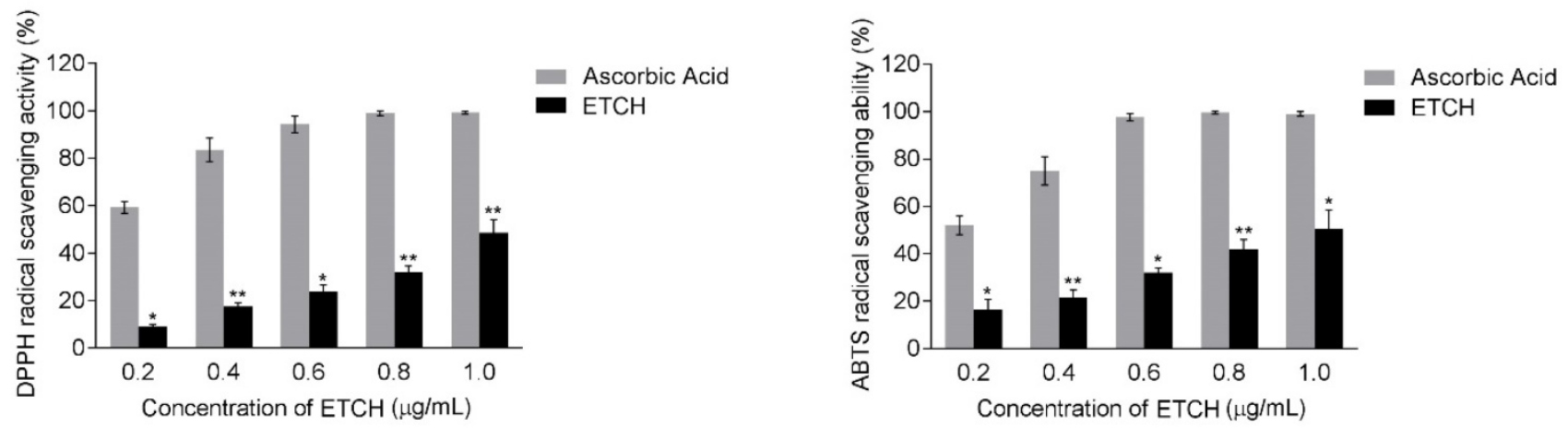

Figure 1. Antioxidant activities of ETCH: DPPH assay and ABTS assay. Data expressed as mean \pm SD for triplicate test. Quantitation of the results from three independent experiments $(n=3)$ is shown as mean \pm SD with statistical significance as $* p<0.05$ and $* * p<0.01$ between the control and ETCH-treated group. 

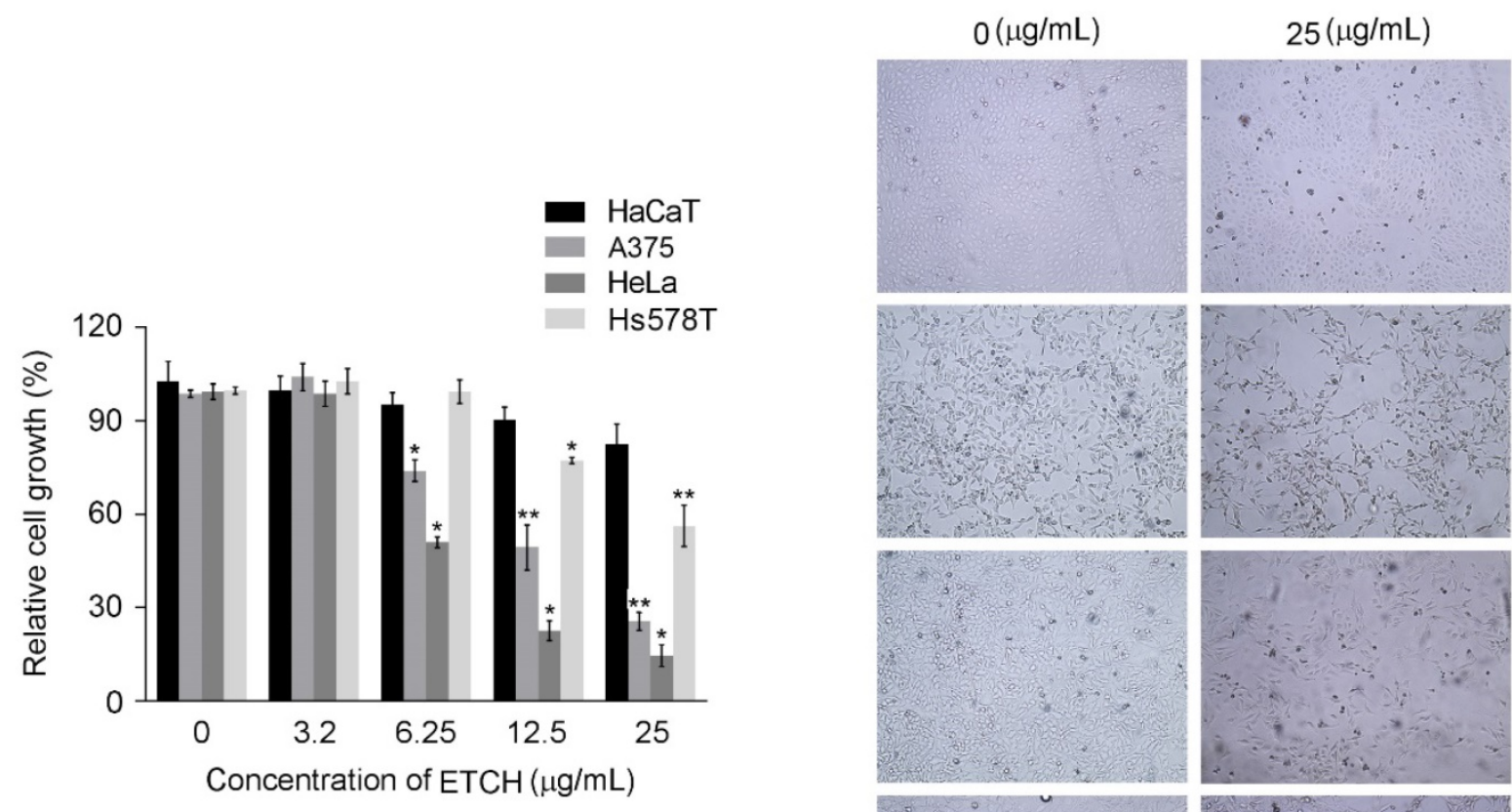

HaCaT
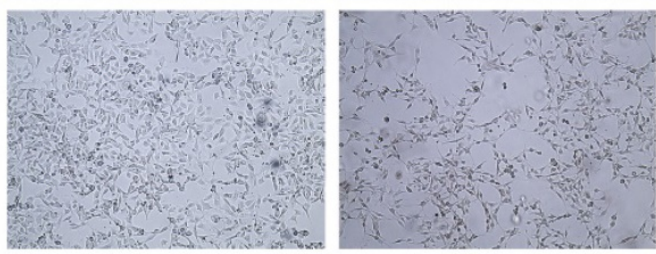

A375
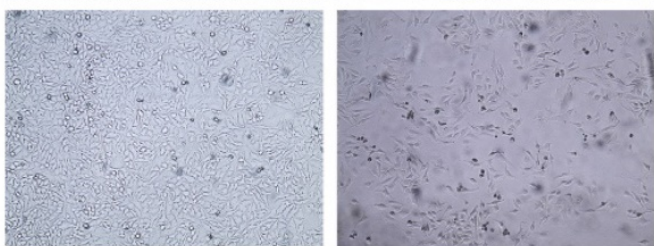

HeLa
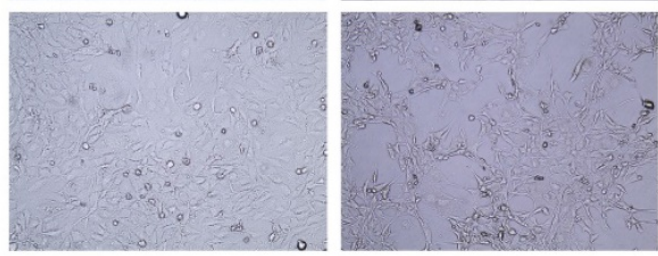

Hs578T

Figure 2. Antiproliferative effect and morphological change of ETCH against human cancer cells. Cells were treated with or without different concentrations (12.5 and $25 \mu \mathrm{g} / \mathrm{mL}$ ) of ETCH for $72 \mathrm{~h}$. The cell viability was assessed by MTT assay. The results are means \pm SD, $n=3$ experiments. $*_{p}<0.01, * * p<0.001$.

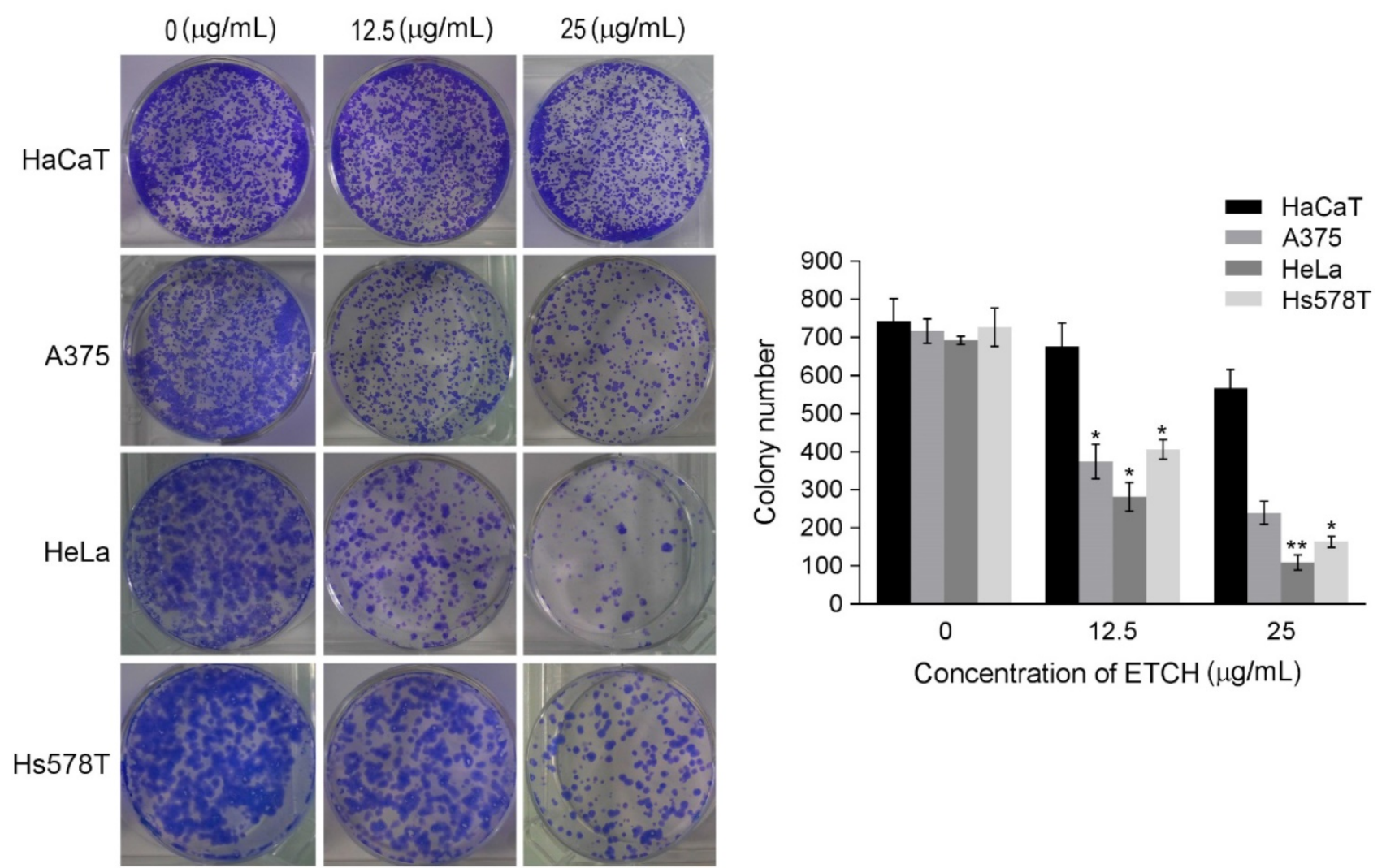

Figure 3. Inhibition on colony formation of cancer cells after ETCH (12.5 and $25 \mu \mathrm{g} / \mathrm{mL}$ ) treatment for $6 \mathrm{~h}$. Experiments were performed three times and the data are presented as the mean \pm SD. $* p<0.05, * * p<0.01$ 
A
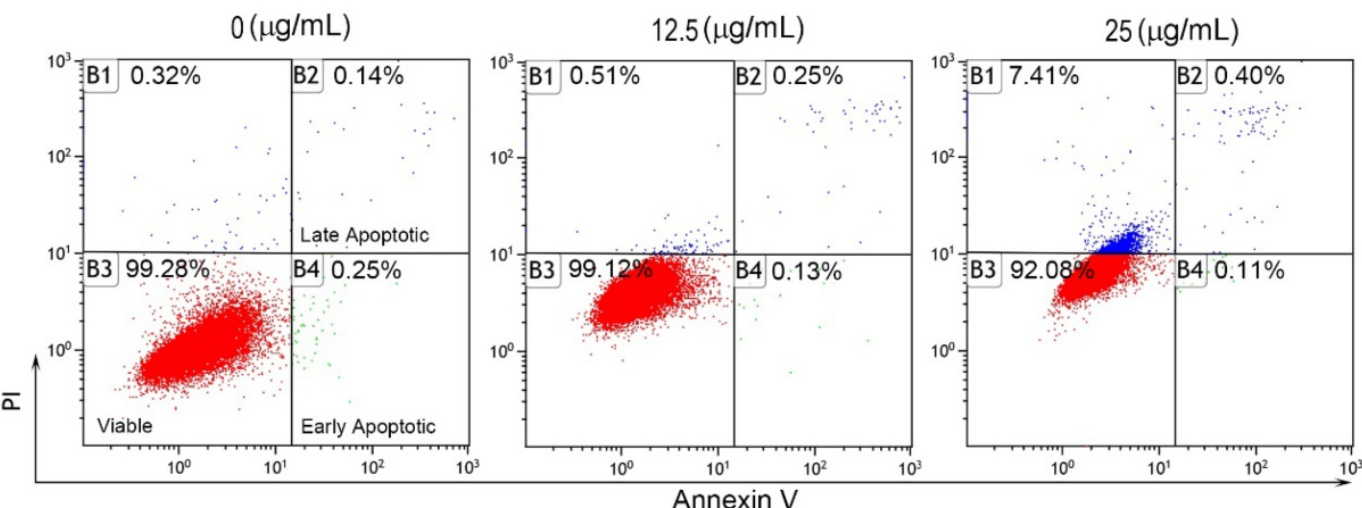

B
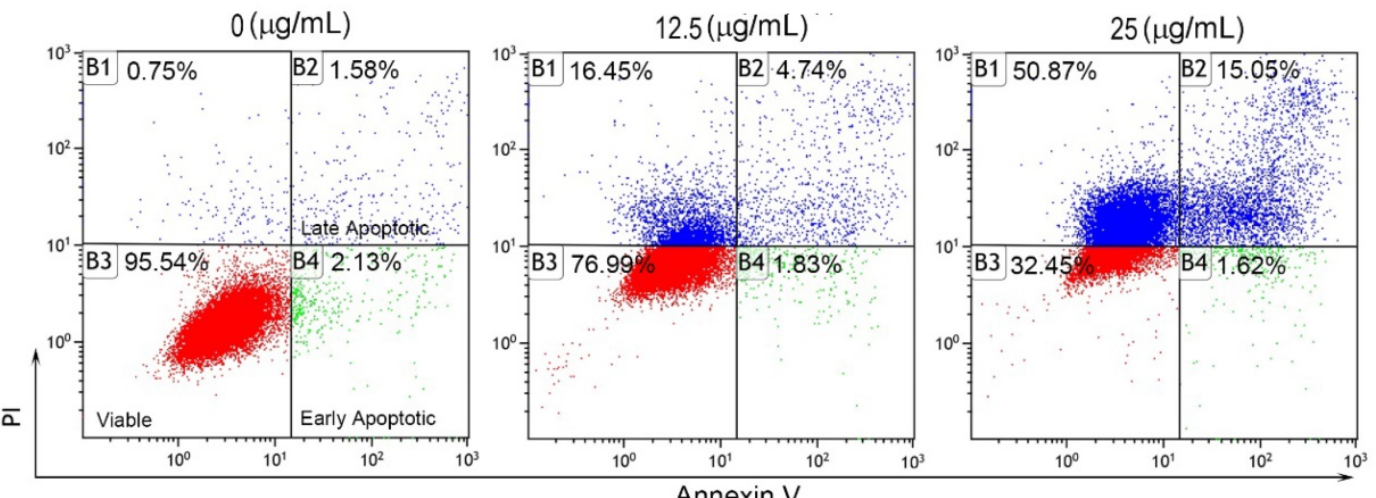

C

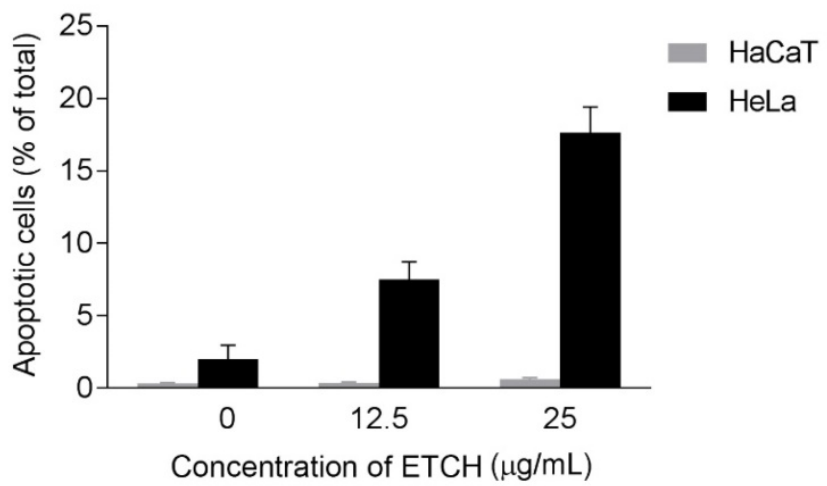

Figure 4. Effect of ETCH on apoptosis. Normal ( $\mathrm{HaCaT})(\mathrm{A})$ and cancer $(\mathrm{HeLa})$ cells $(\mathrm{B})$ were treated with or without different concentrations $(25 \mu \mathrm{g} / \mathrm{mL})$ of $\mathrm{ETCH}$ for $24 \mathrm{~h}$, and was measured by FACS analysis.

\section{ETCH-induced apoptosis through the modulation of apoptosis-associated genes}

Next, we were wondering if a significant anti-proliferation effect of ETCH on the cancer cells might occurred via cellular apoptosis. To verify this possibility, we performed flow cytometric analysis to evaluate healthy (AnnexinV-/FITC-), early apoptotic (Annexin+/FITC), late apoptotic (AnnexinV+/FITC+) and debris (AnnexinV-/FITC + ) cell populations in normal and cancer cells, respectively. Annexin V-positive (early and late apoptosis) cells were considered the apoptotic population. As shown in Fig. 4, the apoptotic population of HeLa cells increased significantly with increasing doses of $\mathrm{ETCH} ; 6.57 \%$ $(12.5 \mu \mathrm{g} / \mathrm{mL})$ and $16.67 \%(25 \mu \mathrm{g} / \mathrm{mL})$, compared with the untreated control group $(3.72 \%)$, whereas apoptosis was not occurred in normal cells in response to ETCH. This observation suggests that the extract selectively induces apoptosis to cancer cells, and not normal cells. Here, due to a similar absorbance range of wavelength between PI and green ETCH, the population of healthy cells treated with ETCH could be overall shifted to PI-staining area. Next, we extended the analysis to explore the effect of ETCH on molecular markers of apoptosis. In order to further understand the mechanisms of ETCH-induced apoptosis, we examined major 
regulators of apoptosis signaling. Consistent with the flow cytometry analysis, there was a considerable decrease in the expression of apoptosis-associated proteins procaspase- 3 and $\mathrm{Bcl}-2$ and increase in cleaved caspase-3 and p53 in a dose-dependent manner (Fig. 5). Taken together, these data suggested that ETCH induces apoptosis in cancer cells through the activation of apoptosis-related signaling pathways.

Procaspase-3

Active caspase-3

GAPDH

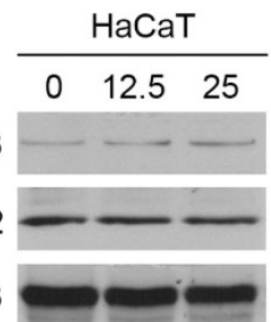

\begin{tabular}{lll} 
HeLa & \\
\hline 0 & 12.5 & 25 \\
$(\mu \mathrm{g} / \mathrm{mL})$
\end{tabular}

p53

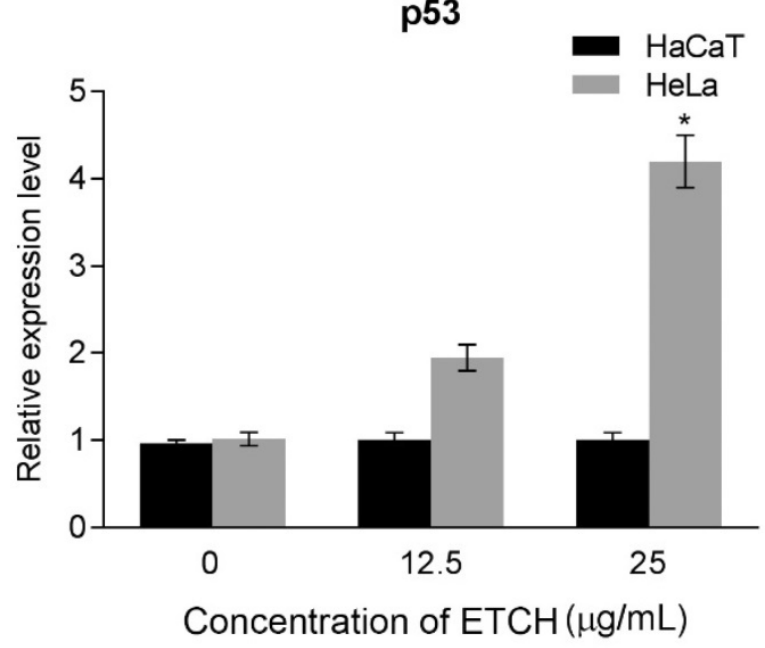

Procaspase-3

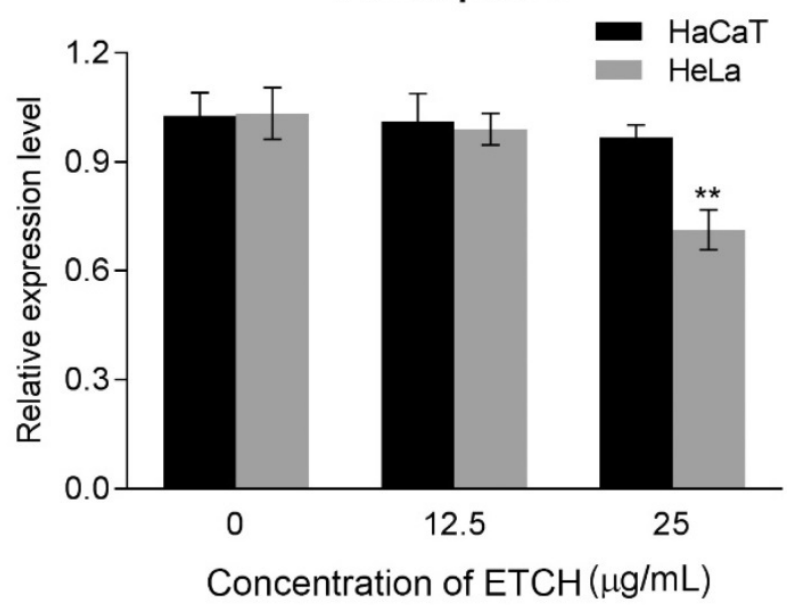

$\mathrm{Bcl}-2$

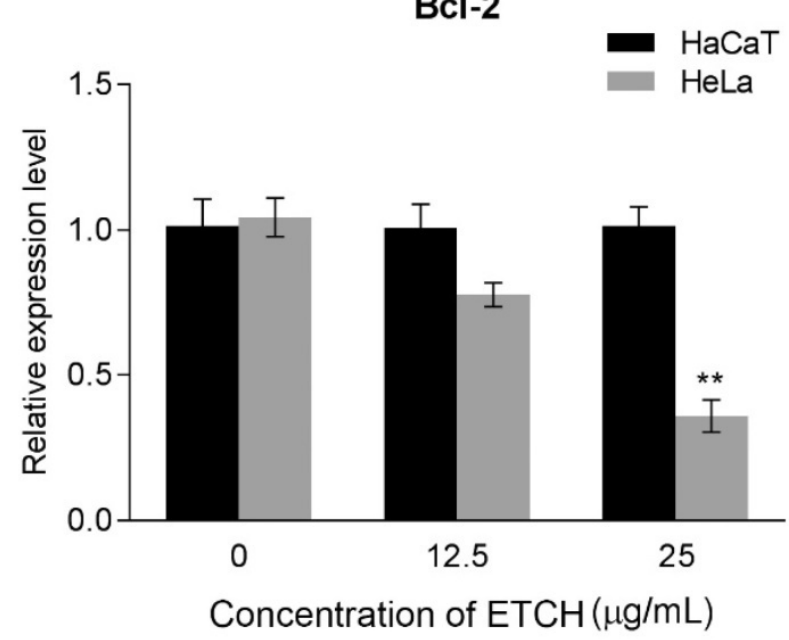

Active caspase-3

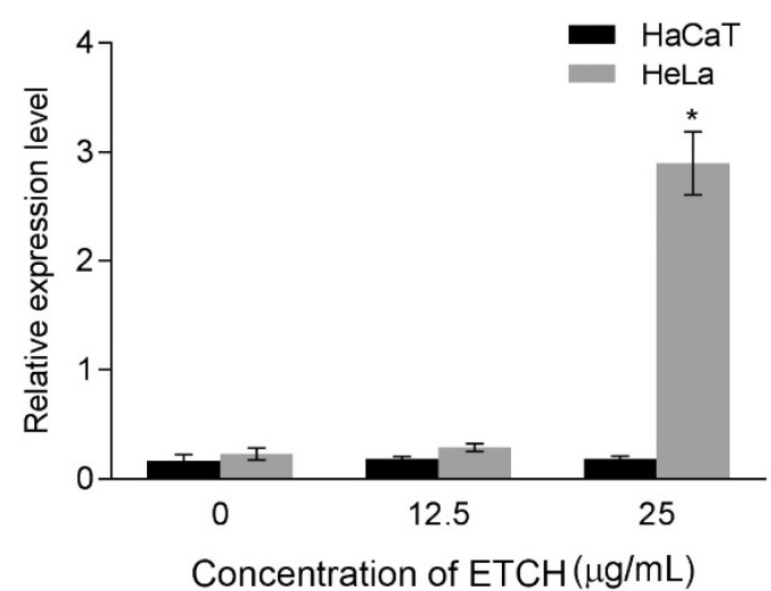

Figure 5. Western blot analysis for apoptosis-related proteins, caspase-3, Bcl-2, and $p 53$. The results are means \pm SD, $n=3$ experiments. $* p<0.05, * * p<0.01$. 


\section{Discussion}

Increasing evidence from cancer studies indicates bioactive compounds derived from the natural sources may act as potentially promising therapeutic agents in the treatment of human cancer [20-22]. In particular, potential anticancer activities of microalgae-derived products have attracted attention in regard to targeted therapies against human cancer and increasingly emphasized that research on microalgal metabolites are useful for the cure of human diseases. In this study, we investigated the role of ETCH from an Antarctic freshwater microalga, Chloromonas sp., inducing anticancer activities in human cancer cells including breast, melanoma, and cervical cancer cells. We demonstrated that ETCH exhibited anti-oxidant capacity and triggered anticancer activities such as anti-proliferation, anti-invasion and apoptotic cell death in cancer cells through the modulation of apoptosis-related genes such as caspase-3, Bcl-2 and p53. To date, this is the first report on the capacity of Antarctic microalgae to exert anticancer activities in human cancer cells. Based on our data, ETCH exhibited a notable anti-proliferative effect in in vitro experiments (Figs 2 and 3), showing a wide spectrum of anti-proliferative effect in different cancer cells. Interestingly, although ETCH induced severe cell anti-proliferation in cancer cells, it was not the case anymore in normal cells. As shown in Fig. 2, the microalgae extract showed less anti-proliferation in normal cells, $\mathrm{HaCaT}$, than in cancer cells, HeLa, A375, and Hs578T, demonstrating that normal cells are less sensitive to ETCH than cancer cells. This fact may provide a clue that ETCH can be a potentially promising candidate for targeted cancer therapies. On the other hand, apoptosis, a programmed form of cell death, is a tightly regulated biochemical process that occurs through a variety of distinct mechanisms associated with the activation of proteases such as caspases that degrade proteins [28]. Members of the caspase family of cysteine proteases play an important role in the effector phase of apoptotic pathways. Among these, caspase-3, considered the most important executioner caspase, is activated by any of the initiator caspases (caspase- $8,-9$ or -10) [29]. In addition, other important regulatory proteins with regard to apoptosis are Bcl-2 and p53; Bcl-2 is specifically considered an important anti-apoptotic protein and is thus classified as an oncogene [30], whereas p53 functions as a tumor suppressor to integrate multiple stress signals into a series of diverse anti-proliferative responses such as cell cycle arrest and induction of apoptosis in cancer cells [31]. In an effort to better understand the possible mechanisms by which ETCH may regulate programmed cell death or apoptosis in cancer cells, we measured caspase-3, Bcl-2 and p53 protein levels, which are associated with apoptosis signaling pathway (Fig. 5). According to our results, our findings provide evidence that ETCH might trigger both early and late stage apoptosis in cancer cells via apoptotic pathway, at least in part by caspase-3 activation. On the other hand, during apoptosis, cells undergo dramatic changes in morphology [29, 32]. For example, apoptotic cells are recognized by stereotypical morphological changes, such as shrinkage, deformation and condensation of chromatin in the nucleus. Cells displaying shrinkage are typically smaller in size, the cytoplasm is dense, and organelles are more tightly packed. Here, we observed characteristic morphological changes in ETCH-treated cancer cells (Fig. 2). Interestingly, no morphological changes occurred in normal cells, reflecting efficient suppression of apoptosis through the inhibition of apoptosis-associated physiological and molecular events. In addition to inducing apoptotic cell death, ETCH retains anti-invasive activity of cancer cells. Metastasis, the leading cause of cancer mortality, is composed of a number of sequential events including invasion. In the invasion process, malignant tumor cells are able to be dissociated from the primary tumor and invade the surrounding tissue through the modulation of proteins involved in the control of cellular motility and migration. In the present study, ETCH significantly inhibited invasion process of cancer cells at low doses relative to those with anti-proliferative effect (Fig. 6). This observation suggests that ETCH may not only contain anti-proliferative compounds but anti-invasive ones which effectively function at low concentration without no effect on cellular proliferation. In summary, we have shown for the first time that an Antarctic microalga has antioxidant activity and induces apoptotic cell death in cancer cells in vitro, through the caspases dependent pathway. In this study, we provide evidence showing that Antarctic microalgae extract could act as a new anti-cancer agent for human cancer by inducing apoptosis and repressing invasion. Further studies are required to explore and identify the responsible components of microalgae extract and their molecular mechanisms.

\section{Acknowledgements}

This research was supported by the research project (PE17180) and K-AOOS (PM16040) of Korea Polar Research Institute, republic of Korea.

\section{Competing Interests}

The authors have declared that no competing interest exists. 

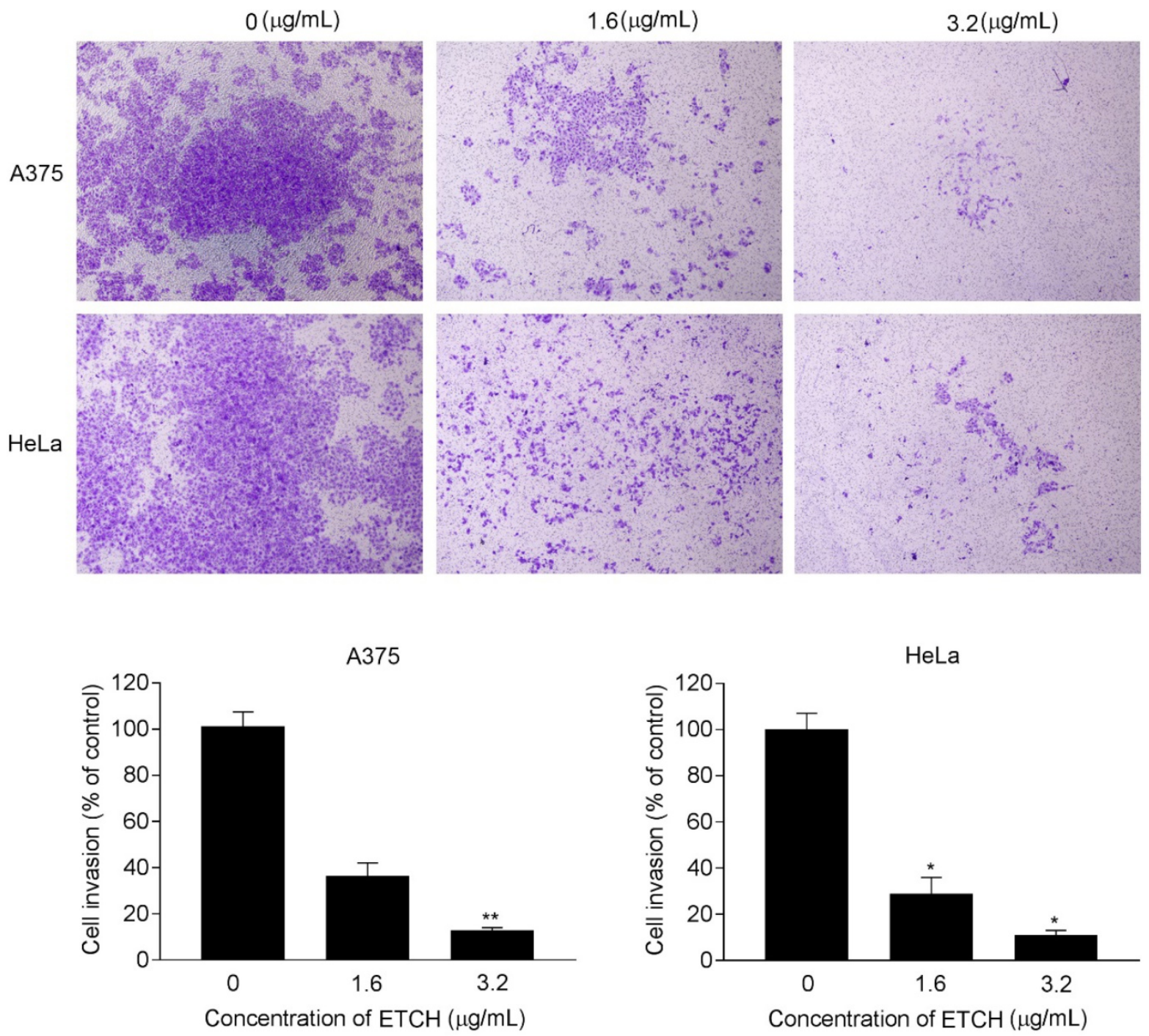

Figure 6. Effect of ETCH on cellular invasion. Cells were treated with or without different concentrations (1.6 and $3.2 \mu g / \mathrm{mL})$ of ETCH for $24 \mathrm{~h}$. Quantitation of the results from three independent experiments $(n=3)$ is shown as mean $\pm S D$ with statistical significance as $*_{p}<0.05$ and $* * p<0.01$.

\section{References}

1. Mantovani A, Allavena P. The interaction of anticancer therapies with tumor associated macrophages. J Exp Med. 2015; 212: 435-45.

2. Gore L, DeGregori J, Porter CC. Targeting developmental pathways in children with cancer: what price success?. Lancet Oncology 2013; 4: e70-8.

3. Dossett LA, Kudchadkar RR, Zager JS. BRAF and MEK inhibition in melanoma. Expert Opin Drug Saf. 2015; 14: 559-70.

4. Kato S, Moulder SL, Ueno NT, Wheler JJ, Meric-Bernstam F, Kurzrock R, et al. Challenges and perspective of drug repurposing strategies in early phase clinical trials. Oncoscience. 2015; 2: 576-80.

5. Vazquez A. Optimization of personalized therapies for anticancer treatment. BMC Syst Biol. 2013; 7: 31 .

6. Basmadjian C, Zhao Q, Bentouhami E, Djehal A, Nebigil CG, Johnson RA, et al. Cancer wars: natural products strike back. Front Chem. 2014; 2: 20

7. Sawadogo WR, Boly R, Cerella C, Teiten MH, Dicato M, Diederich M. A survey of marine natural compounds and their derivatives with anti-cancer activity reported in 2012. Molecules. 2015; 20: 7097-142.

8. Orang-Ojong BB, Munyangaju JE, Wei MS, Lin M, Wei FG, Foukunang C, et al. Impact of natural resources and research on cancer treatment and prevention: A perspective from Cameroon. Mol Clin Oncol. 2013; 1: 610-20.

9. Ko JK, Auyeung KK. Identification of functional peptides from natural and synthetic products on their anticancer activities by tumor targeting. Curr Med Chem. 2014; 21: 2346-56.

10. Giddings LA, Newman DJ. Microbial natural products: molecular blueprints for antitumor drugs. J Ind Microbiol Biotechnol. 2013; 40: 1181-210.
11. Younis KM, Usup G, Ahmad A. Secondary metabolites produced by marine Streptomyces as antibiofilm and quorum-sensing inhibitor of uropathogen Proteus mirabilis. Environ Sci Pollut Res Int. 2016; 23: 4756-67.

12. Cragg GM, Grothaus PG, Newman DJ. Impact of natural products on developing new anti-cancer agents. Chem Rev. 2009; 109: 3012-43.

13. Gimpel JA, Henríquez V, Mayfield SP. In metabolic engineering of eukaryotic microalgae: potential and challenges come with great diversity. Font Microbiol. 2015; 6: 1376.

14. Sharma NK, Rai AK. Biodiversity and biogeography of microalgae: progress and pitfalls. Environ Rev. 2011; 19: 1-15.

15. Shanab SM, Mostafa SS, Shalaby EA, Mahmoud GI. Aqueous extracts of microalgae exhibit antioxidant and anticancer activities. Asian Pac J Trop Biomed. 2012; 2: 608-15.

16. de Morais MG, Vaz Bda S, de Morais EG, Costa JA. Biologically active metabolites synthesized by microalgae. Biomed Res Int. 2015; 2015: 1-15.

17. Martins A, Vieira H, Gaspar H, Santos S. Marketed marine natural products in the pharmaceutical and cosmeceutical industries: tips for success. Mar Drugs. 2014; 12: 1066-101.

18. Dias DA, Urban S, Roessner U. A historical overview of natural products in drug discovery. Metabolites. 2012; 2: 303-36.

19. David B, Wolfender JL, Dias DA. The pharmaceutical industry and natural products: historical status and new trends. Phytochem Rev. 2015; 14: 299-315.

20. Lee JC, Hou MF, Huang HW, Chang FR, Yeh CC, Tang JY, et al. Marine algal natural products with anti-oxidative, anti-inflammatory, and anti-cancer properties. Cancer Cell Int. 2013; 13: 55.

21. Farooqi AA, Butt G, Razzaq Z. Algae extracts and methyl jasmonate anti-cancer activities in prostate cancer: choreographers of the dance macabre'. Cancer Cell Int. 2012; 12: 50. 
22. Talero E, García-Mauriño S, Ávila-Román J, Rodríguez-Luna A, Alcaide A, Motilva

Bioactive compounds isolated from microalgae in chronic inflammation and c ancer. Mar Drugs. 2015; 13: 6152-209.

23. Kumar SR, Hosokawa M, Miyachita K. Fucoxanthin: a marine carotenoid exerting anti-cancer effects by affecting multiple mechanisms. Mar Drugs. 2013; 11: 5130-47.

24. Takahashi K, Hosokawa M, Kasajima H, Hatanaka K, Kudo K, Shimoyama N, et al. Anticancer effects of fucoxanthin and fucoxanthinol on colorectal cancer cell lines and colorectal cancer tissues. Oncol Lett. 2015; 10: 1463-7.

25. Peng J, Yuan JP, Wu CF, Wang JH. Fucoxanthin, a marine carotenoid present in brown seaweeds and diatoms: metabolism and bioactivities relevant to human health. Mar Drugs. 2011; 9: 1806-28.

26. Brand-Williams W, Cuvelier ME, Berset C. Use of a free radical method to evaluate antioxidant activity. Food Sci Technol. 1995; 28: 25-30.

27. Re R, Pellegrini N, Proteggente A, Pannala A, Yang M, Rice-Evans C. Antioxidant activity applying an improved ABTS radical cation decolorization assay. Free Radic Biol Med. 1999; 26: 1231-7.

28. van Zijl F, Krupitza G, Mikulits W. Initial steps of metastasis: Cell invasion and endothelial transmigration. Mutat Res. 2011; 728: 23-34.

29. Elmore S. Apoptosis: a review of programmed cell death. Toxicol Pathol. 2007; 35: 495-516.

30. Danial NN. BCL-2 family proteins: critical checkpoints of apoptotic cell death. Clin Cancer Res. 2007; 13: 7254-63

31. Amaral JD, Xavier JM, Steer CJ, Rodrigues CM. The role of p53 in apoptosis. Discov Med. 2010; 9: 145-52.

32. Saraste A, Pulkki K. Morphologic and biochemical hallmarks of apoptosis. Cardiovasc Res. 2000; 45: 528-37. 